\title{
Addressing Teachers' Feelings of Lack of Control over Policy Issues
}

\author{
Eugene Judson \\ Correspondence: Eugene Judson, Mary Lou Fulton Teachers College, Arizona State University, Tempe, Arizona, \\ United States. E-mail: Eugene.Judson@asu.edu
}

Received: July 3, 2013 Accepted: July 15, 2013 Online Published: October 21, 2013

doi:10.11114/jets.v2i1.171

URL: http://dx.doi.org/10.11114/jets.v2i1.171

\begin{abstract}
This study reports on how an American Education System course, traditionally taught with broad objectives, was contextualized for science teachers. Using pre-assessment data, specific policy issues were targeted with the objective of increasing teachers' feelings of influence over issues. The approach used was adapted from exposure therapy, a method common in behavioral therapy. This involved providing greater depth of understanding of issues, revisiting issues repeatedly, and developing professional dialogue. After participating in the course, teachers were significantly less likely to list standardized testing and curriculum standards as critical issues. The teachers correspondingly significantly increased their internal locus of control over these issues.
\end{abstract}

Keywords: locus of control, policy issues, teacher preparation, science teacher preparation

\section{Background}

The concept of locus of control first emerged in the field of psychology in the 1950s. Simply stated, this is a framework for understanding individuals' perceptions of their control over events (Rotter, 1954). A locus of control orientation can range from believing outcomes are outside of personal control to believing outcomes are wholly contingent on personal actions (Zimbardo, 1985). People possess an internal locus of control when they believe their own behaviors and abilities can significantly influence consequences; similarly, an external locus of control leads people to believe that consequences are determined on external factors such as luck or powerful administrative forces (Janssen \& Carton, 1999; Rotter, 1966). Locus of control ideas are related to attribution research that has examined how people often attribute success to their own abilities while attributing failures to influences outside of themselves. An attribution perspective indicates that people often make causal analysis in a self serving manner (Fiske \& Taylor, 1991; Weiner, 1986). A common example of this is a student who is proud of a good grade when he or she states "I earned an A!" versus that same student receiving a poor grade and transferring responsibility to a teacher when exclaiming "You gave me an F!"

It is generally considered that having a strong internal locus of control contributes to psychological well being, and may even play a role in physical well being (Gale, Batty, \& Deary, 2008). In the workplace, an internal locus of control can positively affect attitudes and performance, including having positive perceptions about tasks and greater job motivation ( $\mathrm{Ng}$, Sorensen, \& Eby, 2006). These positive attitudes can consequently produce a greater commitment to one's organization (Sunbul, 2003). Alternatively, possessing a consistent external locus of control at the workplace can lead to job dissatisfaction and burnout (Alarcon, Eschleman, \& Bowling, 2009; Crothers, Kolbert, \& Kachmar, 2010).

Although research related to locus of control has been broad, some educational researchers have examined teachers' locus of control in the context of feelings of control over student outcomes, and control over reinforcements particular to a school environment. Sunbul (2003) investigated the role that locus of control plays in teacher burnout. Results indicated that possessing an external locus of control was a significant predictor of the emotional exhaustion dimension of burnout among teachers. Similarly, Halpin, Harris, and Halpin (1985) examined self-reported data from 130 teachers and concluded that locus of control was significantly correlated to feelings of stress. Teachers possessing an external locus of control, and as a result greater stress, tended to align with sentiments such as not seeing a clear connection between effort and payoff in teaching; not feeling influential in their educational environment; and believing that luck, and not personal effort, played a large role in the fate of their profession. On the other hand, the researchers also concluded that teachers possessing a strong internal locus of control were more likely to accept responsibilities of all types (e.g., student performance, school policies) and were inclined to accept responsibility for their own actions, believing that their work does contribute to personal 
and school-wide goals. In turn, this can lead to teachers participating voluntarily more in decision making processes at a school and developing positive attitudes of empowerment (Bogler \& Somech, 2004).

Possession of a strong external locus of control among teachers is connected directly to anxiety and feelings of low degree of influence on policies and issues that affect day to day routine. Specific policy issues are often associated with teachers' stress and feelings of efficacy, or lack thereof (Evans, 2009; Tolbert, 2007). This is an important topic because teacher stress, related to feelings of lack of control, can lead to emotional exhaustion and increased absenteeism that in turn affect student performance (Gulek, 2003; Yoon, 2002).

While there is prevalent research documenting the connection between teacher stress resulting from being overwhelmed with multiple policy issues such as standardized testing and school accountability, less is known about how best to support these stressed teachers. Largely what exists are general ways to support teachers by developing feelings of professionalism and control, such as through peer mentoring and collaborative problem solving (e.g., Hatch, White, \& Faigenbaum, 2005; Smylie, 1996). To provide support for teachers, it was believed that a framework for therapy could be borrowed and adapted from the field of psychology to ease apprehensive feelings of having little control over policy issues. Exposure therapy is more commonly associated with anxiety disorders such as a fear of flying or a fear of insects, but it is an established behavioral therapy that can be applied to many situations, including stressful situations developed in the workplace (Nucifora, Langlieb, Siegal, Everly, \& Kaminsky, 2007). The case is not being made that feeling stressed due to not having influence over a school policy issue is on par with severe anxiety disorders that can manifest as terrible panic attacks; rather, it is supposed that exposure therapy has value when considering helping teachers who feel they are powerless to influence policy issues.

The essential approach of exposure therapy involves confronting a feared situation in a controlled environment. The facets of exposure therapy, adapted for use in this study, were the following:

- Develop an understanding of the topic in order to erase fears of the unknown.

- Sustain attention on the topic to create habituation and decrease anxiety.

- Maintain ongoing dialogue about the topic so it becomes less daunting.

In the above, the word "topic" has replaced the word "fear" that is more ordinarily used. Fear represents a specific aversion such as spiders or germs. However, it is not assumed that teachers have actual fears of policy issues, but may instead possess general anxiety and at times even avoidance of policy issues.

\section{Setting}

Consolidation of the colleges of education located on the different campuses of a large Arizona university, plus a partnership with Teach for America, led to large enrollments in master of education programs. This allowed for content-based graduate student cohorts to be formed made up of masters students who were concurrently full-time teachers. Following their first summer of professional development, these graduate students begin full-time teaching duties and are in charge of their own classrooms. During their first two years, leading to certification, these in-service teachers continue to attend courses in the evenings, are formally supervised by university personnel, and complete action research projects. Thanks to extensive recruitment efforts to enlist new teachers of secondary education in science, mathematics, and special education, these areas have had enough students to warrant their own cohorts.

Although the students were grouped into cohorts based on their content, not all of the coursework had been tailored along those content lines. The American Education System course was such a class that continued to be taught in a conventional manner. The objectives of this course are broad, but the intent is to provide students with an understanding of the political, social, and economic forces that shape American schools. Students in this course have traditionally examined various topics including seminal court cases that have impacted education, school finance mechanisms, school board structuring, and the general history of the American education system. The author was assigned to teach a section of the American Education System course for the secondary science education cohort. This presented an opportunity to customize the course for science teachers. While the chief objectives of the course remained intact, there was latitude to integrate readings related to science, technology, engineering, and mathematics (STEM) education, to focus discussions on concerns specific to science teaching, and to frame general education topics within the context of science education. Additionally, a signature assignment for the course was for the students to develop a policy brief on a topic they considered needed attention from policymakers. Students most often chose to focus their policy brief project on a non-science related topic such as school lunch nutrition and community service requirements; however, approximately one-third of the students selected topics that were specific to science education. Examples of science specific 
policy brief topics included the future of common science standards across the states and science course-taking requirements within a school district.

It was decided that the customization of this course would focus on topics which students both believed to be critical and which they felt they had relatively little influence over. The expectation, if not the optimistic hope, was that by dedicating energy to delve into topics meeting this double criteria of a) being considered critical and b) outside of one's locus of control, as compared to other topics, that students would emerge with improved feelings of influence and, as a result, less anxiety. The goal was to increase the teacher's internal locus of control over chosen policy issues. Following the tenets of exposure therapy outlined, the approach was to return to selected issues repeatedly throughout the semester, work toward developing shared understanding of the history and implications of those topics, and promote targeted discourse among the teachers about those topics.

\section{Pre-assessment Results}

A good deal of deliberation was spent on selecting an instrument to measure the teachers' locus of control. Many fine, but generalized, instruments exist to measure individuals' locus of control (e.g., Rotter, 1966). However, as indicated by Bezjak and Lee (1990), instruments tailored for specific groups and circumstances lead to better predictions about actual behavior. Therefore a brief survey was designed that was specific to assessing the science teachers' feelings of locus of control and their influence over various educational policies. On the first day of the semester the science teachers anonymously completed this brief survey regarding policy issues and feelings of influence.

Participants were all full-time classroom teachers and at the point of this course, they were in the second semester of their second year of full-time teaching. Their experience allowed them to respond to the survey with the insight they had gained as classroom teachers. The first portion of the survey prompted them to list what they believed were the three most critical educational policy issues affecting teachers, students, and schools. Some listed only two issues. The teachers then rated the degree to which they believed they were able to influence each of their listed issues on a one to four-point Likert scale, from no ability to influence to great ability to influence; these were considered their influence ratings.

The second portion of the survey had a parallel structure in that it also prompted students to list issues and rate their perceived degree of influence on each listed issue. However, the second portion of the survey asked about policy issues affecting science teaching and learning, whereas the first portion of the survey requested responses about educational policy issues in general. The reasons behind dividing the survey into two sections (i.e., general educational issues and science education issues) were to (a) allow the science teachers to express critical policy issues they believed were particular to science education, and (b) discern if the course could address issues from both angles of general education and science education.

Twenty-one teachers completed the pre-assessment survey. As stated, the teachers were prompted to provide three general educational policy issues they believed to be critical and to rate each of these on a scale ranging from one to four to indicate their perceived level of control (i.e., influence ratings). Likewise, the teachers followed this same format of listing critical policy issues and rating their perceived levels of control over science education policy issues. One student listed and rated two, instead of three, general education topics. Three students listed and rated two, instead of three, science education topics. All other students listed and rated three general education policy issues and three science education policy issues.

The responses were grouped into categories. For example, if a teacher listed mandated district standardized testing as a critical issue and another teacher listed required state standardized testing as a critical issue, these were grouped under the same category of Standardized Testing. The most expansive category was Budget \& Salaries. Among the science specific responses, the Budget \& Salaries category included responses such as "insufficient funding for science equipment" and "science classrooms are overcrowded because of inadequate school funding." Similarly, when categorizing the general education issues, the Budget \& Salaries category was the widest and included responses about sports programs being cut due to lack of funding and teacher salaries being low compared to other professions. The Special Populations category included references to the issue of developing individualized educational plans (IEPs) for English language learners, mainstreaming special education students into the classroom, and providing resources for students of migrant families. The Classroom Instruction category included mentions of classroom curriculum, course sequencing, and instructional practices.

It is noted that the responses from the surveys were categorized by the author alone. This did not provide an opportunity to determine the inter-rater reliability of the process. However, considering the succinct responses that the teachers provided (typically no more than three or four words), it was not necessary to apply any high level of inductive coding that would have necessitated a second rater to ensure fidelity of the process. Provided 
in Tables 1 and 2 are the most common issues that were listed by the teachers and the corresponding mean influence ratings for general educational policy issues and science education policy issues, respectively. Tables 1 and 2 include only those topics that were listed at least five times on either the pre or post-survey.

Table 1. Most common general education issues listed by teachers and influence ratings

\begin{tabular}{lccrrrc}
\hline \multirow{2}{*}{ Topic } & \multicolumn{3}{c}{ Quantity } & \multicolumn{5}{c}{ Mean Influence Rating } \\
& Pre & Post & Pre (SD) & Post (SD) & $t$ & $p$ \\
\hline Standardized Testing & 14 & 4 & $1.5(0.5)$ & $2.2(0.5)$ & 2.57 & $.061^{*}$ \\
Budget \& Salaries & 11 & 15 & $1.7(0.6)$ & $1.8(0.8)$ & 0.26 & .878 \\
School Accountability & 9 & 7 & $1.8(1.0)$ & $1.9(0.7)$ & .19 & .758 \\
State Curriculum Standards & 8 & 5 & $1.3(0.5)$ & $2.4(0.5)$ & 3.90 & $.011^{* *}$ \\
Special Populations (ELL, SPED, Migrant) & 6 & 2 & $2.1(1.0)$ & $3.0(0.0)$ & 1.14 & .429 \\
Classroom Instruction & 3 & 6 & $3.3(0.6)$ & $2.7(1.0)$ & 1.24 & .381 \\
Teacher Certification & 2 & 8 & $2.0(0.0)$ & $2.6(0.7)$ & 1.14 & .400 \\
\hline
\end{tabular}

$* p \leq 0.1 * * p \leq 0.05$

Appearing most frequently among both the educational policy issues and the science education policy issues were Standardized Testing, Budget \& Salaries, and State Curriculum Standards. The issue of School Accountability was cited frequently (nine times) on the pre-assessment as a general educational policy issue of concern, but it was cited only once on the pre-assessment as a science education policy concern. Other issues, not listed in either Table 1 or Table 2, because they were not cited at least five times on either the pre or post-survey, included school policy to promote parental involvement, charter school regulation, teacher certification, school board authority, school lunch nutrition, formal feedback from school administrators, and technology use policies.

Table 2. Most common science education issues listed by teachers and influence ratings

\begin{tabular}{lccccccc}
\hline \multirow{2}{*}{ Topic } & \multicolumn{2}{c}{ Quantity } & \multicolumn{5}{c}{ Mean Influence Rating } \\
& Pre & Post & Pre (SD) & Post (SD) & $t$ & $p$ \\
\hline State Curriculum Standards & 11 & 8 & $1.6(0.5)$ & $2.3(0.5)$ & 2.75 & $.062^{*}$ \\
Standardized Testing & 10 & 7 & $1.8(0.6)$ & $2.6(0.8)$ & 1.50 & $.088^{*}$ \\
Budget \& Salaries & 10 & 17 & $1.6(0.7)$ & $1.8(0.6)$ & .634 & .505 \\
Special Populations (ELL, SPED, Migrant) & 6 & 0 & $1.5(0.8)$ & - & & - & - \\
Classroom Instruction & 7 & 11 & $2.3(0.8)$ & $2.9(0.8)$ & 1.64 & .211 \\
\hline
\end{tabular}

$* p \leq 0.1$

The pre-assessment results guided the instructor's decisions regarding how to customize the course for the science teachers. Most of the topics that the science teachers had listed in their pre-survey were already included among the topics of the American Education System course. If the critical issues listed by the teachers were viewed as areas needing attention, a simple approach could have been to just state the traditional planned course already addressed these topics and therefore met the needs. Policy issues such as curriculum standards, school finance, and standardized testing were already touched upon within the standard textbook and conventionally these topics received a dedicated amount of course time. However, in the past, these topics had been addressed only broadly and were not delivered to students in any content specific manner. In previous semesters, any content-specific variation within the course stemmed from the students themselves through the projects and presentations they developed, but not from the instructor. Importantly, in the past, due to the wide scope of the course, topics were introduced and concluded over a short period of time.

To assess which topics should receive greater attention the metric of an Urgency Rating (UR) was devised to incorporate both the frequency a policy issue was mentioned and the mean influence ratings. The frequency a policy issue was mentioned and the mean influence ratings were given equal weight to calculate the UR. Frequency weight (FW) was calculated as the average mentions of a topic per student (i.e., number of times a topic was listed divided by the number of students). FW could range from zero to one. To work out an equivalent weight from the mean influence ratings, the following equation was used to calculate the influence weight (IW): IW $=(4-\mathrm{MI}) / 3$, where MI is equal to the mean influence rating. Parallel to the FW, the IW could range from zero to one. For example, had all 21 teachers listed teacher certification as a critical area and all had rated their influence on this issue to be at the lowest level of one, then the FW would be calculated as $21 / 21=1$ and the IW would be calculated as $(4-1) / 3=1$. The UR was calculated by adding the FW and IW: UR $=$ FW + IW. The UR is a statistic invented for this project and was intended only as a tool to help direct the instructor's attention. The UR can range in value from zero to two and was calculated only for those issues that were listed by at least five teachers. The URs were calculated for both the general educational policy issues and the science education policy issues (Table 3). 
Table 3. Urgency ratings (UR) calculated from pre-survey data

\begin{tabular}{lcccc}
\hline & \multicolumn{3}{c}{ General Education } & \multicolumn{2}{c}{ Science Education } \\
Topic & Pre & Post & Pre & Post \\
\hline Standardized Testing & 1.5 & 0.8 & 1.2 & 0.8 \\
State Curriculum Standards & 1.3 & 0.8 & 1.3 & 0.9 \\
Budget \& Salaries & 1.3 & 1.4 & 1.3 & 1.5 \\
Special Populations (ELL, SPED, Migrant) & 0.9 & 0.4 & 1.1 & - \\
Classroom Instruction & 0.4 & 0.7 & 0.9 & 0.9 \\
School Accountability & 1.2 & 1.0 & - & - \\
Teacher Certification & 0.8 & 0.8 & - & - \\
\hline
\end{tabular}

Because the UR can range from zero to two, the midpoint value of 1.0 was considered a tipping point. The UR calculations yielded three topics with values greater than 1.0 in both the general education and science education categories: State Curriculum Standards, Standardized Testing, and Budget \& Salaries. The topic of Special Populations was above the 1.0 tipping point in only the science education category. The instructor decided that extra emphasis would be placed on the State Curriculum Standards and Standardized Testing issues. The topics of Budget \& Salaries and Special Populations would still be addressed within the course, but would follow the more traditional approach. In addition to the UR data, the decision to develop new curriculum in support of the State Curriculum Standards and Standardized Testing issues was based on both the instructor's expertise in these areas and the fact that these issues lent themselves well to being contextualized within science education.

\section{Course Customization}

The ideas of exposure therapy were used as a means for considering how to structure an approach. It is underscored that it was never imagined that the teachers suffered from intense phobias; it was though believed that the general ideas of exposure therapy provided a useful frame upon which to attach concrete plans. Following this line of thought, it was important to work through a process of 1) familiarizing, 2) continuing exposure, and 3) developing dialogue as custom. Just as someone who is deathly afraid of snakes is obviously aware of snakes, the teachers were undoubtedly familiar with curriculum standards and standardized testing. The objective of familiarizing is to move beyond superficial awareness and begin to develop expert knowledge. Following familiarization, it is important to not regard the treatment as a single inoculation - that is, continued exposure through various activities is necessary. Finally, the activities must be supportive of the teachers developing a professional dialogue about curriculum standards and standardized testing.

\subsection{Customizing to Address State Curriculum Standards}

Regarding curriculum standards, these second year science teachers were already acquainted with the six strands (e.g., Inquiry Process, Physical Science) that comprise the Arizona Science Standards and the underlying concepts and performance objectives. As an example of how the Arizona Science Standards are laid out, within the Physical Science strand are five Concepts (e.g., Motion and Forces), and within each of these Concepts are specific performance objectives delineated by grade level (e.g., eighth-grade students are to demonstrate velocity as the rate of change of position over time). Some of the teachers shared that at times they felt a preoccupation to cover the many performance objectives and were concerned that they were not always providing the necessary amount of class time to address these in depth. It was believed by the instructor that many of the teachers were caught up in a proverbial dilemma of not being able to see the science standard forest for the trees. Therefore, the approach here was not to merely spend more time looking at the science standards, but instead to provide a more extensive and substantial picture of the science standards. Developing this more comprehensive picture would include reflecting on one's personal perspective about the science standards, learning about the history of the standards movement in general, knowing about important international comparisons that have pointed to a need for science standards, examining how the science standards and inquiry-based pedagogy can correspond, and discovering how the development of new science standards can be influenced by teachers.

A first step toward creating this wider view of science standards was to encourage teachers to look inward and assess their attitudes toward the science standards. This was accomplished through a two step activity. First, all of the teachers were assigned to read the article High School Science Teachers' Views of Standards and Accountability (Donnelly \& Sadler, 2009) and write a related personal reflection that demonstrated a consideration of the major points of the article and provided connections between the article and personal thoughts about learning science. The Donnelly and Sadler article provides a brief recent history of the development of science standards by pointing to the calls for scientific literacy that prompted the National Science Teachers Association (NSTA), the National Research Council (NRC), and the American Association for the Advancement of Science (AAAS) to develop different, but overlapping, forms of science standards. The authors 
also highlight that those documents guided the states in fulfilling the mandates of the No Child Left Behind Act of 2001 as states developed standards and standards-based assessments in content areas, including science.

Donnelly and Sadler identified from their work six profile types among science teachers that typify science teachers' views of state science standards. These included profiles such as a viewing the standards as useful tools, believing that standards are just part of the continuous cycle of educational change, and having a negative view of the standards (e.g., too broad, or just not useful). Through a student-led activity, the teachers in the American Education course reflected and assessed what type of profile best described themselves. Although many of the teachers had difficulty assigning their views to fit neatly into just one profile, the exercise led to greater discussion about the science standards and how the teachers wished to feel about the science standards versus their actual sentiments. Generally, most of the teachers had some negative views about the standards, but also saw them at times as being useful tools and viewed standards as simply part of the reality of their classroom and school. None of the teachers in the class viewed the standards as part of a continuous educational cycle, but did state that they knew more experienced teachers possessing this perspective.

Later in the semester the students read and reflected on the article Facing Facts in U.S. Science and Mathematics Education: Where We Stand, Where We Want to Go (McKnight \& Schmidt, 1998) and similarly followed this with an in-class activity. With the advantage of hindsight, the teachers read this article that examined math and science data from the 1996 Third International Mathematics and Science Study (TIMSS). The article focuses on the eighth-grade data and reveals that the United States was about average in science among TIMSS countries and below average in math achievement. An important aspect of the article was that it brought attention to the wide array of topics covered in first through twelfth grade in the United States. The course instructor emphasized that the article was published a few years before NCLB legislation was enacted, at a time when it was not uncommon for school districts to follow their own content standards. The call to action of McKnight and Schmidt also paralleled a trend in the country to deal with the "mile wide, inch deep" issue of science curriculum in the United States. This picture of science in our schools as being quite splintered and lacking a clear vision was a strong rationale for common standards within each state.

The teachers in the course resolved in groups that since the publication of the McKnight and Schmidt article, that the country had made great strides in establishing content standards. However, in small group discussion, the teachers also pointed out that while a set of state standards can be viewed as meeting the call to have a "coherent, selective vision focused on clear, shared goals" (p.75), there has not been much progress made in developing a consistent instructional approach in science classrooms. The teachers believed that science instruction requirements were still less cognitively demanding than other countries and that teachers in the United States still often present science as a series of vocabulary lessons. In fact, some of the teachers felt that the current science standards prompted them to deliver these types of vocabulary lessons because at times they saw no other effective means to address all of the performance objectives.

In addition to the two aforementioned examples of lessons based on science policy articles, other lessons integrated a similar sequence of having students read and reflect on articles followed by in-class small and large group discussion activities. There is certainly nothing astounding about this sequence of activities; the noteworthy elements are that this was done to address a need rated highly by the URs, was contextualized instruction for science teachers within the broader goals of the American Education System course, and adhered to exposure therapy by returning to a topic repeatedly with the goal of lessening anxiety and improving feelings of influence.

The topic of curriculum standards was further dealt with by addressing the inquiry strand of the science standards and how inquiry can facilitate comprehending traditional science disciplines. This was approached by having the teachers read, reflect, and discuss the chapter Scientific Inquiry and How People Learn in the book How Students Learn: Science in the Classroom (Donovan \& Bransford, 2005). The chapter focuses on the need to address preconceptions, how students can learn science as a process of inquiry, and the importance of metacognition. Reading a book chapter, writing a reflection paper, and participating in consequent discussions does not turn a didactic teacher into a student-centered teacher - this was not the intention. The purpose here was to draw attention to how the often ignored content strand of inquiry could be leveraged to fulfill larger goals of pressing students to think critically while also meeting traditional content objectives. The in-class activity centered on examining performance objectives from the Arizona Science Standards and discussing how these could be addressed both through traditional means of informing students and through inquiry.

The last agenda item related to the content standards was to have the teachers examine the conceptual science framework from the NRC that had been put out for public comment the summer that preceded this course. The teachers worked through an exercise of exploring the framework to distinguish notable changes from the current state science standards and discussed their views about the need for a new set of science standards and the direction they perceived the conceptual framework to be headed. Here again face-to-face discussion was an 
important aspect so that dialogue about science standards could become customary and professional. The teachers were also provided information regarding how to be notified when NRC and Achieve released updates regarding the Next Generation Science Standards.

\subsection{Customizing to Address Standardized Testing}

Similar to the topic of the science standards, standardized testing was addressed by designing a series of learning activities centered on specific readings. The readings were followed by personal reflections and then in-class activities that involved both small and large group discussions. It was important that the topics were selected based on teachers' pre-assessment results, that these topics were revisited repeatedly in order to develop fluency and confidence, and there was a deliberate goal of positively impacting teachers' locus of control.

It was quickly realized through discussions with the teachers that standardized testing apprehensions were mostly related to the state mandated Arizona Instrument to Measure Standards (AIMS) assessments and end-of-course tests required by many of the school districts. AIMS is a high-stakes test and its results used to calculate Adequate Yearly Progress (AYP) which contributes to determining if sanctions are applied by the state department of education to schools that do not meet specific performance criteria. One means to assuage some anxiety was to discuss in class how, although science was tested by AIMS, only achievement results from reading and math contributed to AYP calculations in Arizona. Several teachers admitted to being unaware that the science results were used only for general reporting, but were not a factor in school accountability. This led to further discussion of opinions regarding if science should indeed be included in AYP calculations. This discussion included references to research demonstrating that states that have chosen to include science results in accountability formulas have increased their science achievement in the elementary grades significantly more than other states (Judson, 2010; Judson, 2012).

In-class discussion activities related to standardized testing stemmed from two important pieces of writing. The first was Aligning Classroom-Based Assessment with High-Stakes Tests (Pasquale \& Grogan, 2008). Here the authors discuss various formats of questions found on standardized tests and how each type can be used by teachers to inform instruction and evaluate learning. In the class, the teachers examined science items from AIMS, TIMSS, the National Assessment of Educational Progress (NAEP), and the Massachusetts Comprehensive Assessment System (MCAS). This led to rich discussion about variability of science items within the tests and comparisons of the tests. Importantly, the teachers became more aware of the availability of released items and gained a formatted means to analyze test items.

The second important reading about standardized testing was Systems for State Science Assessment: Findings of the National Research Council's Committee on Test Design for K-12 Science Achievement (Bertenthal, Wilson, Beatty, $\&$ Keller, 2008). The authors summarize findings of a task committee of the NRC regarding guidance to states on how to develop quality science assessments that meet NCLB requirements. The teachers in the class found the recommendation from the NRC to the states to develop "a system of science assessment that collectively would meet the various purposes of NCLB" (p. 309) particularly interesting because, other than a single test being used to sample multiple groups, the teachers and instructor were unaware of any full-scale science assessment system. This spurred discussion of the realities of budgets that limit widespread assessment systems and the possibilities of what could be done to tie together local and statewide assessment systems. The reading also stimulated discourse about the use of classroom assessment and how these are sometimes misaligned with instruction; specifically, some teachers acknowledged that while their planned instruction appeared to be student-centered and required critical thinking, that a lack of time often left them using standard tests from textbooks.

Additional attention to standardized testing was paid through shorter activities and handouts. This included discussion of the "Texas miracle" wherein the apparent astonishing progress of students on a state assessment was brought into doubt due to various factors including missing data, test validity, misclassification of students, and lack of corresponding evidence from other assessments or graduation rates (Haney, 2000). The executive summary from the article How Teaching Matters: Bringing the Classsroom Back Into Discussions of Teacher Quality (Wenglinsky, 2000) was also used to highlight how science scores on a standardized science test were significantly higher when students had been performing hands-on learning activities and taking frequent point-in-time tests. Finally, because many of the teachers expressed that when preparing students for standardized tests it was customary to drill only on similarly formatted test items, assessment items from the book Uncovering Student Ideas in Science (Keeley, Eberle, \& Farrin, 2005) were used to demonstrate how performance objectives from the Arizona Science Standards could be assessed in ways that probe and challenge thinking while also preparing students for a standardized test.

\section{Post-assessment Results}

After concluding the course, the teachers completed a post-survey that contained the same questions as the pre-survey. Again, the teachers indicated what they considered to be the three most critical policy issues both 
generally in education and more specifically in science education. Once more, the number of times that particular topics were mentioned was summed and the mean influence ratings were calculated (Tables 1 and 2). Examining the targeted topics of State Curriculum Standards and Standardized Testing, fewer teachers cited these issues on the post-survey than did on the pre-survey in both the general education and science education categories. The mean influence ratings also increased for both State Curriculum Standards and Standardized Testing - this signifying an increase in teachers' internal locus of control over these issues.

State Curriculum Standards and Standardized Testing were the topics to which exposure therapy were applied. These topics had been selected because they had high UR scores and because they could straightforwardly be contextualized within science education. Other topics, such as Budget \& Salaries and Special Populations, were addressed in the course in a traditional manner. Among these other topics, there were some notable changes. On the post-survey, the Budget \& Salaries topic became the most mentioned policy issue in both the general education and science education areas. This was particularly evident in the science education area where ten teachers mentioned salaries and budgets as a critical issue on the pre-survey and 17 of the teachers mentioned it on the post-survey (Table 2). The influence that teachers felt they had over Budget \& Salaries remained essentially unchanged. Additionally, there was a somewhat surprising drop in the amount of teachers who listed Special Populations as a critical issue both among the general education and science education policy issues.

A series of Mann-Whitney $U$ tests were conducted to determine if there were significant differences between the mean influence ratings on the pre- and post-surveys (Tables 1 and 2). The Mann-Whitney U test was selected because it is a conservative approach appropriate for the nonparametric data examined. The statistical analysis was considered only a broad estimate of differences because of the nature of the open-ended responses of the data. That is, the teachers were not provided one specific list of policy issues and asked to rate each one. Instead, the constructed response items of the surveys allowed teachers to provide a wide range of answers. Additionally, because data were collected anonymously, the comparisons were made between non-paired responses. Analysis indicated there were significant changes at the level of $p$ less than 0.05 in general education on the policy issue of State Curriculum Standards $(p=.011)$. At the level of $p$ less than 0.1 , there were significant changes in general education on the policy issue of Standardized Testing $(p=0.61)$ as well as in science education on the policy issues of State Curriculum Standards ( $p=.062)$ and Standardized Testing $(p=0.88)$.

Overall, the number of issues (including those mentioned fewer than five times) in the general education and science education increased from the pre- to post-survey. In the general education category, the issues of parent involvement, nutrition, school scheduling, and teacher retention were mentioned only on the post-survey. In the science education category, the issues of science in the elementary grades, low enrollment in science courses, international comparisons, teacher retention, and women in science were mentioned only on the post-survey.

The URs were calculated from the post-survey responses and compared to the pre-survey URs (Table 3). The greatest changes were among the targeted topics of Standardized Testing and State Curriculum Standards. The UR for the non-targeted issue of Special Populations also experienced a change of similar magnitude in the general education category. The topic of Special Populations was not listed at all among the critical topics in the science education category on the post-survey. As stated, the UR is a statistic devised to draw needed attention to topics that the teachers felt were critical and over which they felt they had relatively little control. Calculations of the URs from the post-surveys suggest that the teachers are less apprehensive about Standardized Testing and State Curriculum Standards but have perhaps become more uneasy about the issue of Budget \& Salaries.

\section{Conclusion}

These data denote that the course was successful on the whole in decreasing teachers' concerns and increasing their internal locus of control over the two targeted topics of Standardized Testing and State Curriculum Standards. Because fewer teachers listed these two issues among what they perceived to be the most critical policy issues on the post-survey and because the mean influence ratings increased significantly for these issues there is support for the exposure method used. By the end of the course the science teachers felt they had significantly greater influence over curriculum standards and over standardized testing. Of course, actual ability to affect these policy issues did not change, but perception of ability to impact these issues did transform and became more positive.

Although there was not a significant change in the mean influence ratings related to the issue of Budget \& Salaries, substantially more teachers did list this as a critical issue on their post-survey (Table 3). This obliges reflection as to why this became a more critical issue for many of the teachers. One possible reason is that as teachers abandoned other topic areas such as Special Populations and Standardized Testing as being among the most critical policy issues, that they then included the likely suspect of Budgets and Salaries. However, within the course the issue of school finance was dealt with differently than other topics, and that may have also led to increased concern. School finance was the only topic that was addressed with the use of a guest speaker. The school finance director from the state department of education visited the class to provide a presentation about the 
state of school finance and to answer questions. This was an extensive, yet rushed presentation, that covered numerous topics including how average daily membership (ADM) is calculated, how school districts receive funding for transportation costs, formulas to determine state aid to schools, federal funding, the process of applying for school repairs, funding for charter schools, etc. No aspect of the school finance presentation was placed in the context of science education. For example, there was not a discussion about how schools typically budget for disposable supplies needed for science experiments. The presentation and question period lasted more than two hours. Although the students were able to ask the finance director several questions, there was not time for student-to-student discussion. The students were appreciative to have such an expert visit the class, but many commented afterward about how the flood of information left them feeling a bit overwhelmed. Other than a reading which was not discussed in class, the teachers did not have any other exposure to school finance in this course.

Though it was not planned as such, the Budget \& Salaries issue may then serve as a counterpoint to the Standardized Testing and State Curriculum Standards issues. The large amount of school finance information provided in one large dose possibly inundated the science teachers and only made them more apprehensive. However, the method of revisiting a policy issue repeatedly, viewing the issue within the context of science, and developing shared understanding through planned discussions, appears to be a process that made inroads toward helping teachers feel more at ease with the issues of Standardized Testing and State Curriculum Standards both in the broad context of education and the more finite context of science education.

Fewer teachers listed Standardized Testing and State Curriculum Standards as critical policy issues. Among the teachers still listing these as critical issues, there was a significant increase in feelings of influence. It is then conjectured that these policy issues ended up yielding less stress among the teachers. Further research is needed to ferret out this speculation that stress is reduced through this type of exposure therapy method. Similarly, it is necessary to further investigate whether other issues, particularly that of school finance, become more nerve-racking. Notwithstanding, this study provides a demonstration that a general course like American Education System can be contextualized for science teachers to meet overall course objectives and address specific interests of science teachers. Additionally, the study provides indication that applying the tenets of exposure therapy can aid in easing concerns about specific policy issues and can increase feelings of internal locus of control.

\section{References}

Alarcon, G., Eschleman, K. J., \& Bowling, N. A. (2009). Relationships between personality variables and burnout: A meta-analysis, Work \& Stress, 23(3), 244-263. http://dx.doi.org/10.1080/02678370903282600

Judson, E. (2010). Science education as a contributor to adequate yearly progress and accountability programs. Science Education, 94(5), 888-902. http://dx.doi.org/10.1002/sce.20396

Judson, E. (2012b). When science counts as much as reading and mathematics: An examination of differing state accountability policies. Education Policy Analysis Archives, 20(26), 1-26. Retrieved from http://epaa.asu.edu/ojs/article/view/987

Bertenthal, M. W., Wilson, M. R., Beatty, A., \& Keller, T. E. (2008). Systems for state science assessment: Findings of the National Research Council's committee on test design for k-12 science achievement. In J. Coffey, R. Douglas \& C. Stearns (Eds.), Assessing science learning: Perspectives from research and practice (pp. 301-316). Arlington, VA: NSTA Press.

Bezjak, J. E., \& Lee, J. W. (1990). Relationship of self-efficacy and locus of control constructs in predicting college students' physical fitness behaviors. Perceptual and Motor Skills, 71(2), 499-508. http://dx.doi.org/10.2466/pms.1990.71.2.499

Bogler, R., \& Somech, A. (2004). Influence of teacher empowerment on teachers' organizational commitment, professional commitment and organizational citizenship behavior in schools. Teaching and Teacher Education, 20(3), 277-289. http://dx.doi.org/10.1016/j.tate.2004.02.003

Crothers, L. M., Kolbert, J. B., \& Kachmar, S. P. (2010). Job stress and locus of control in teachers: Comparisons between samples from the United States and Zimbabwe. International Review of Education, 56(5/6), 651-669. http://dx.doi.org/10.1007/s11159-010-9176-6

Donnelly, L. A., \& Sadler, T. D. (2009). High school science teachers' views of standards and accountability. Science Education, 93(6), 1050-1075. http://dx.doi.org/10.1002/sce.20347

Donovan, M. S., \& Bransford, J. D. (Eds.). (2005). How students learn: Science in the classroom. Washington, D.C.: National Academy Press.

Evans, A. (2009). No Child Left Behind and the quest for educational equity: The role of teachers' collective sense of efficacy. Leadership and Policy in Schools, 8(1), 64-91. http://dx.doi.org/10.1080/15700760802416081 
Fiske, S. T., \& Taylor, S. E. (1991). Social cognition. New York: McGraw-Hill.

Gale, C. R., Batty, G. D., \& Deary, I. J. (2008). Locus of control at age 10 years and health outcomes and behaviors at age 30 years: The 1970 British cohort study. Psychosomatic Medicine, 70(4), $397-403$. http://dx.doi.org/10.1097/PSY.0b013e31816a719e

Gulek, C. (2003). Preparing for high-stakes testing. Theory Into Practice, 42(1), 42-50. http://dx.doi.org/10.1207/s15430421tip4201_6

Halpin, G., Harris, K., \& Halpin, G. (1985). Teacher stress as related to locus of control, sex and age. Journal of Experimental Education, 53(3), 136-140.

Haney, W. (2000). The myth of the Texas miracle in education. Education Policy Analysis Archives, 8(41). Retrieved from http://epaa.asu.edu/ojs/article/view/432

Hatch, T., White, M. E., \& Faigenbaum, D. (2005). Expertise, credibility, and influence: How teachers can influence policy, advance research, and improve performance. Teachers College Record, 107(5), 1004-1035. http://dx.doi.org/10.1111/j.1467-9620.2005.00502.x

Janssen, T., \& Carton, J. S. (1999). The effects of locus of control and task difficulty on procrastination. Journal of Genetic Psychology, 160(4), 436-442. http://dx.doi.org/10.1080/00221329909595557

Keeley, P., Eberle, F., \& Farrin, L. (2005). Uncovering student ideas in science, vol. 1: 25 formative assessment probes. Arlington, VA: NSTA Press. http://dx.doi.org/10.2505/9780873552554

McKnight, C. C., \& Schmidt, W. H. (1998). Facing facts in U.S. science and mathematics education: Where we stand, where we want to go. Journal of Science Education and Technology, 7(1), 57-76. http://dx.doi.org/10.1023/A:1022536200005

Ng, T. W. H., Sorensen, K. L., \& Eby, L. T. (2006) Locus of control at work: A meta-analysis. Journal of Organizational Behavior, 27(8), 1057-1087. http://dx.doi.org/10.1002/job.416

Nucifora, F., Langlieb. A. M., Siegal, E., Everly, G. S., \& Kaminsky, M. (2007). Building resistance, resilience, and recovery in the wake of school and workplace violence. Disaster Medicine and Public Health Preparedness, 1(Supplement 1), S33-S37. http://dx.doi.org/10.1097/DMP.0b013e31814b98ae

Pasquale, M., \& Grogan, M. (2008). Aligning classroom-based assessment with high-stakes tests. In J. Coffey, R. Douglas \& C. Stearns (Eds.), Assessing science learning: Perspectives from research and practice (pp. 283-300). Arlington, VA: NSTA Press.

Rotter, J. B. (1954). Social learning and clinical psychology. New York: Prentice-Hall. http://dx.doi.org/10.1037/10788-000

Rotter, J. B. (1966). Generalized expectancies for internal versus external control of reinforcement. Psychological Monographs, 80(1), 1-28. http://dx.doi.org/10.1037/h0092976

Smylie, M. A. (1996). From bureaucratic control to building human capital: The importance of teacher learning in education reform. Educational Researcher, 25(9), 9-11. http://dx.doi.org/10.3102/0013189X025009009

Sunbul, A. M. (2003). An analysis of relations among locus of control, burnout and job satisfaction in Turkish high school teachers. Australian Journal of Education, 47(1), 58-73. http://dx.doi.org/10.1177/000494410304700105

Tolbert, M. D. (2007). No teacher left behind: A predictive model of teacher stress and coping. Unpublished doctoral dissertation, University of South Carolina.

Weiner, B. (1986). An attributional theory of motivation and emotion. New York: Springer-Verlag. http://dx.doi.org/10.1007/978-1-4612-4948-1

Wenglinsky, H. (2000). How teaching matters: Bringing the classroom back into discussions of teacher quality. Princeton, NJ: Educational Testing Service Policy Information Center.

Yoon, J. S. (2002). Teacher characteristics as predictors of teacher-student relationships: Stress, negative affect, and self-efficacy. Social Behavior and Personality, 30(5), 485-494. http://dx.doi.org/10.2224/sbp.2002.30.5.485

Zimbardo, P. (1985) Psychology and life. Glenview, IL: Scott Foresman.

\section{$(\mathrm{cc}) \mathrm{BY}$}

This work is licensed under a Creative Commons Attribution 3.0 License. 